\title{
Effects of diet on development and reproduction of the predatory pentatomids Picromerus bidens and Podisus maculiventris
}

\author{
K. Mahdian $\cdot$ J. Kerckhove $\cdot$ L. Tirry $\cdot$ P. De Clercq
}

Published online: 2 March 2007

(C) IOBC 2007

\section{Erratum to: BioControl (2006) 51: 725-739 \\ DOI 10.1007/s10526-005-5253-3}

The last author's name was misrepresented in the online metadata of the original article.

The online version of the original article can be found at http://dx.doi.org/10.1007/s10526-005-5253-3

K. Mahdian · J. Kerckhove $\cdot$ L. Tirry $\cdot$ P. De Clercq $(\square)$

Laboratory of Agrozoology, Department of Crop Protection, Faculty of Bioscience

Engineering, Ghent University, Coupure Links 653, B-9000 Ghent, Belgium

e-mail: patrick.declercq@ugent.be

K. Mahdian

Department of Crop Protection, Faculty of Agriculture, Vali-E-Asr University of Rafsanjan, Rafsanjan, Iran 